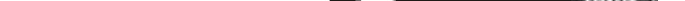





\title{
O grafismo das cestarias dos Guarani M’byá
}

\author{
José Francisco Sarmento*
}

Este trabalho é um recorte da dissertação de mestrado Etnodesign: um estudo do grafismo das cestarias dos M'byá Guarani de Paraty-Mirim (RJ), que trata do entendimento dos significados dos desenhos das cestarias dos índios m'byá guarani, da aldeia Itatins, localizada em Paraty-Mirim, no litoral do Rio de Janeiro. As manifestações estéticas indígenas foram estudadas como sistemas de representação, que procuram explicar como a sociedade pensa a si própria e o mundo que a rodeia, traduzindo essas noções ao nosso próprio sistema cognitivo. Berta Ribeiro acrescenta que "...não há contradição, mas íntima correlação, entre o cuidado do detalhe, próprio à descrição etnográfica, e a validade e a generalidade que reivindicamos para o modelo construído a partir dela" (Ribeiro, 1987, p.23).

* Graduado e Mestre em

Design pela Pontifícia Universidade Católica do Rio de Janeiro (PUC-Rio), professor da Universidade Católica Dom Bosco (UCDB) desde 1997. Pesquisador do Núcleo dos Estudos e Pesquisas das

Populações Indígenas (NEPPI-UCDB). jose.sarmento@terra.com.br 

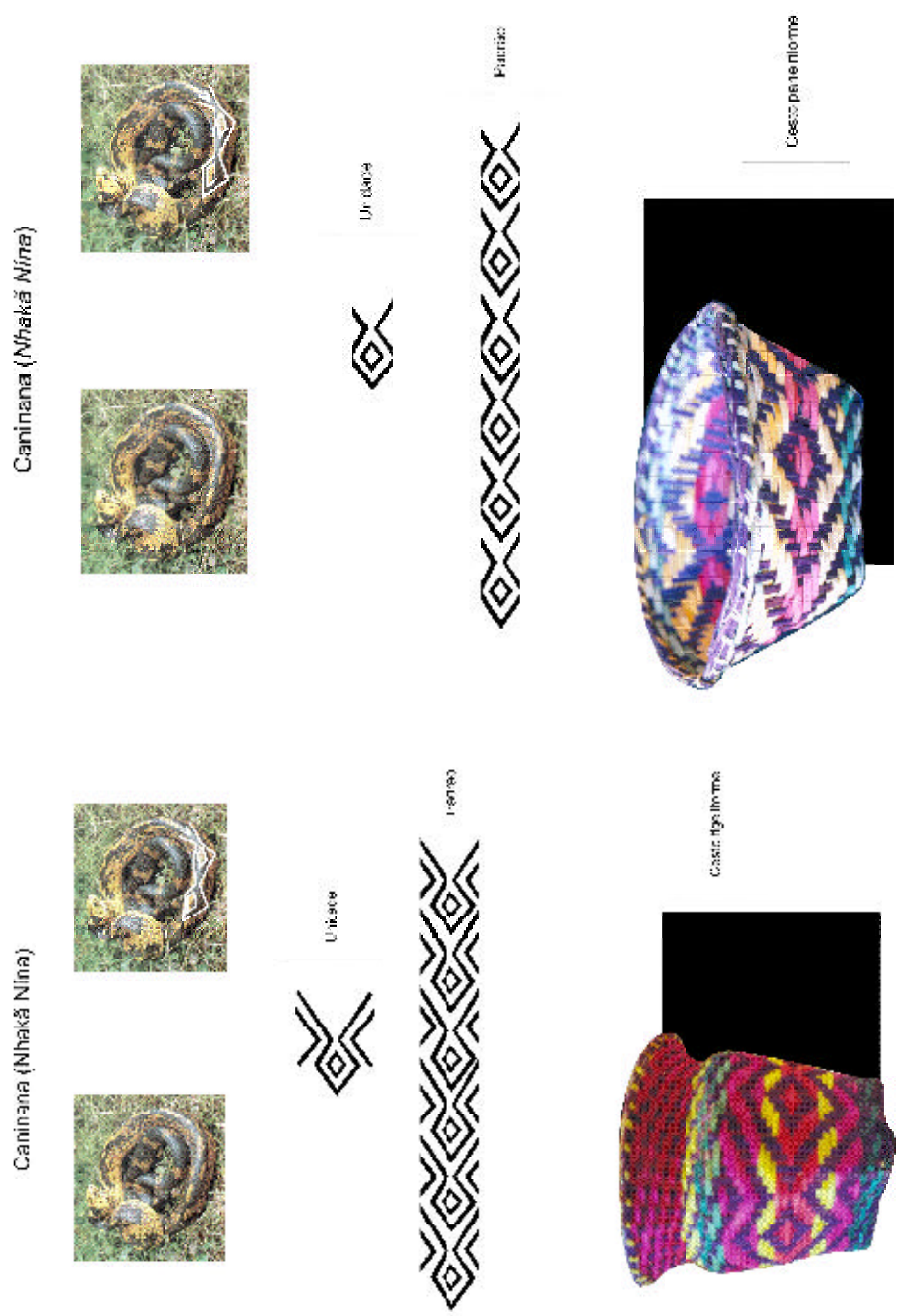

214 Francisco José SARMENTO. O grafismo das cestarias dos Guarani M’byá 

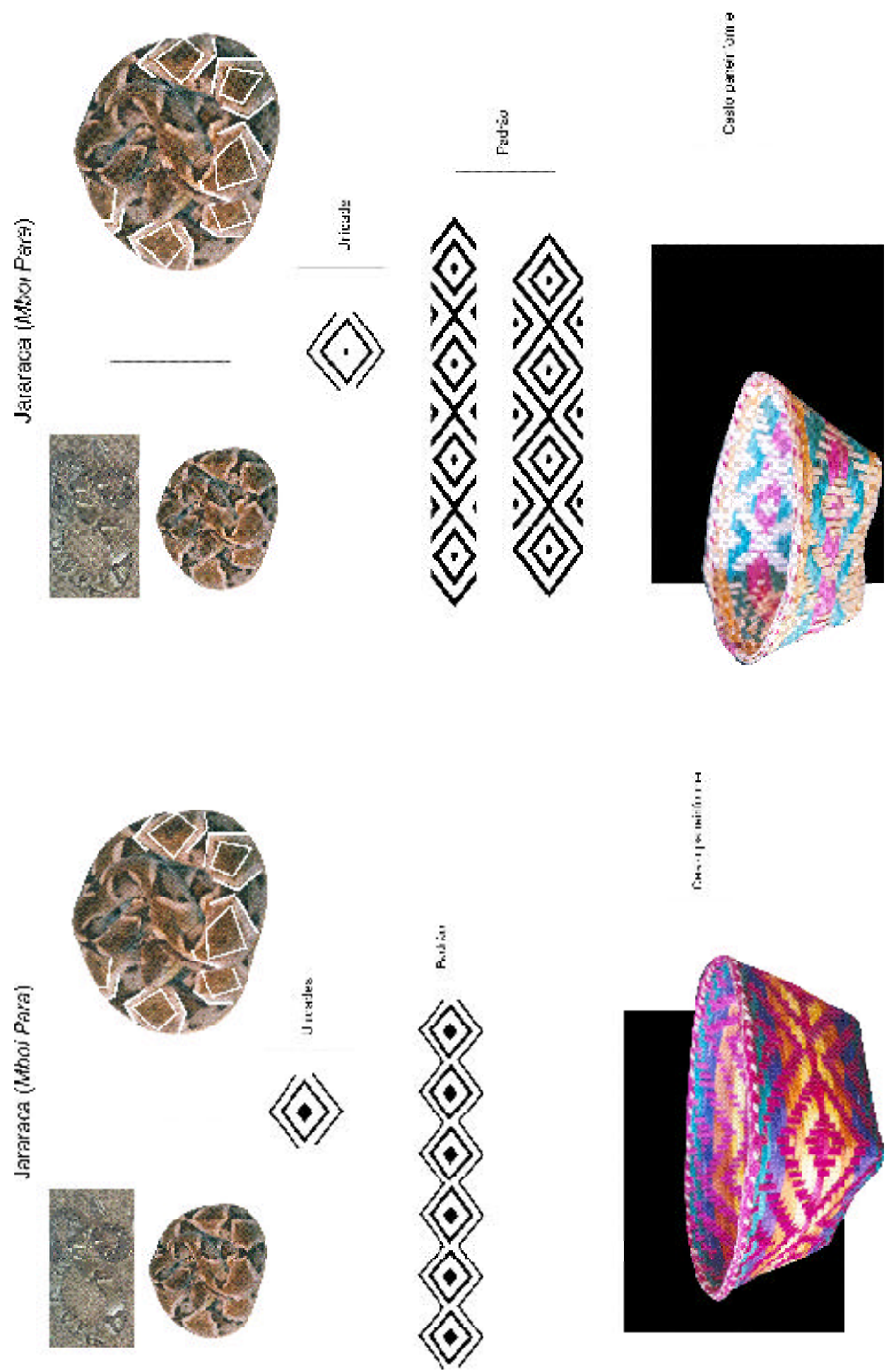

Tellus, ano 8, n. 15, jul./dez. 2008 

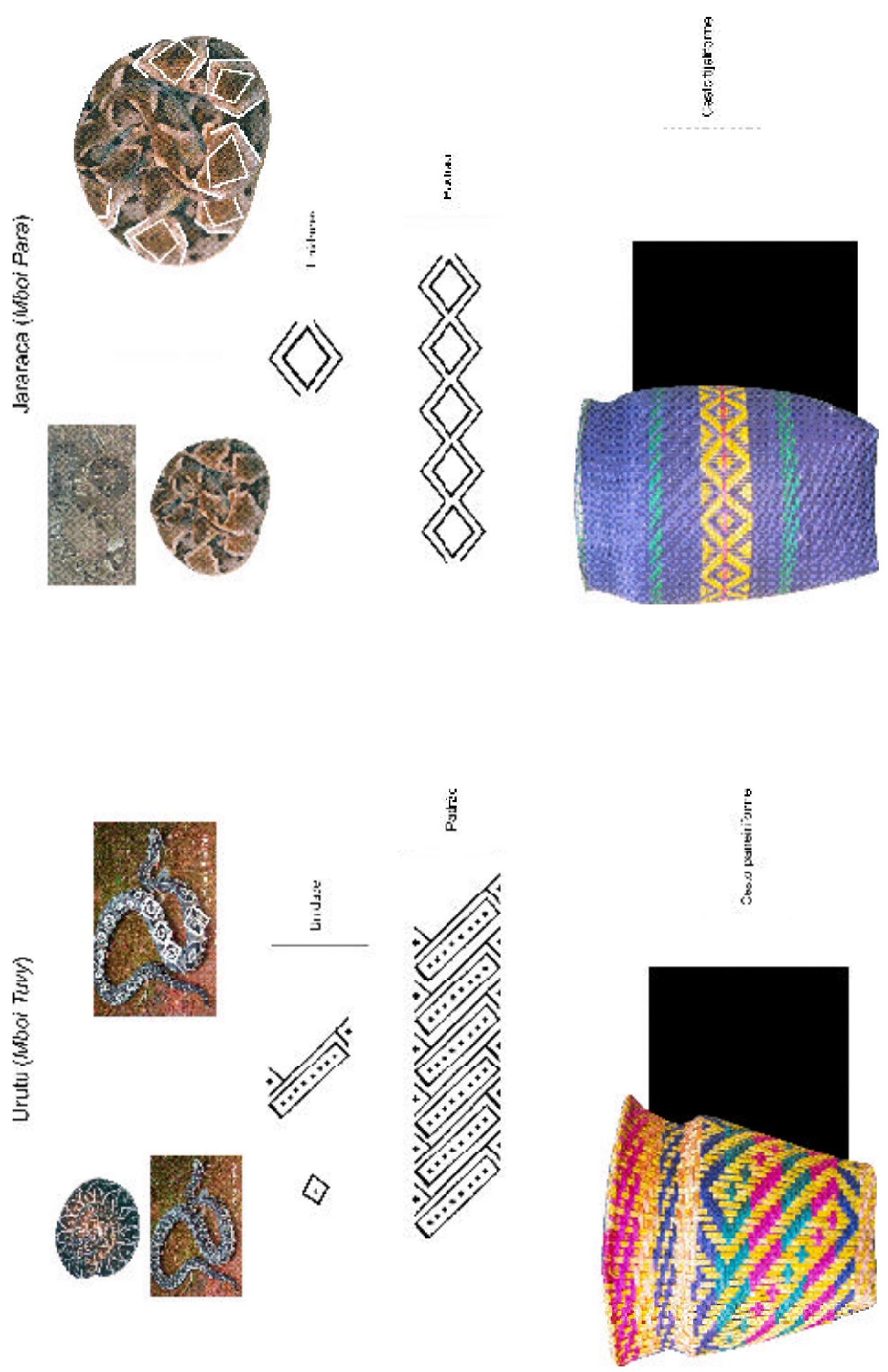

216 Francisco José SARMENTO. O grafismo das cestarias dos Guarani M'byá 

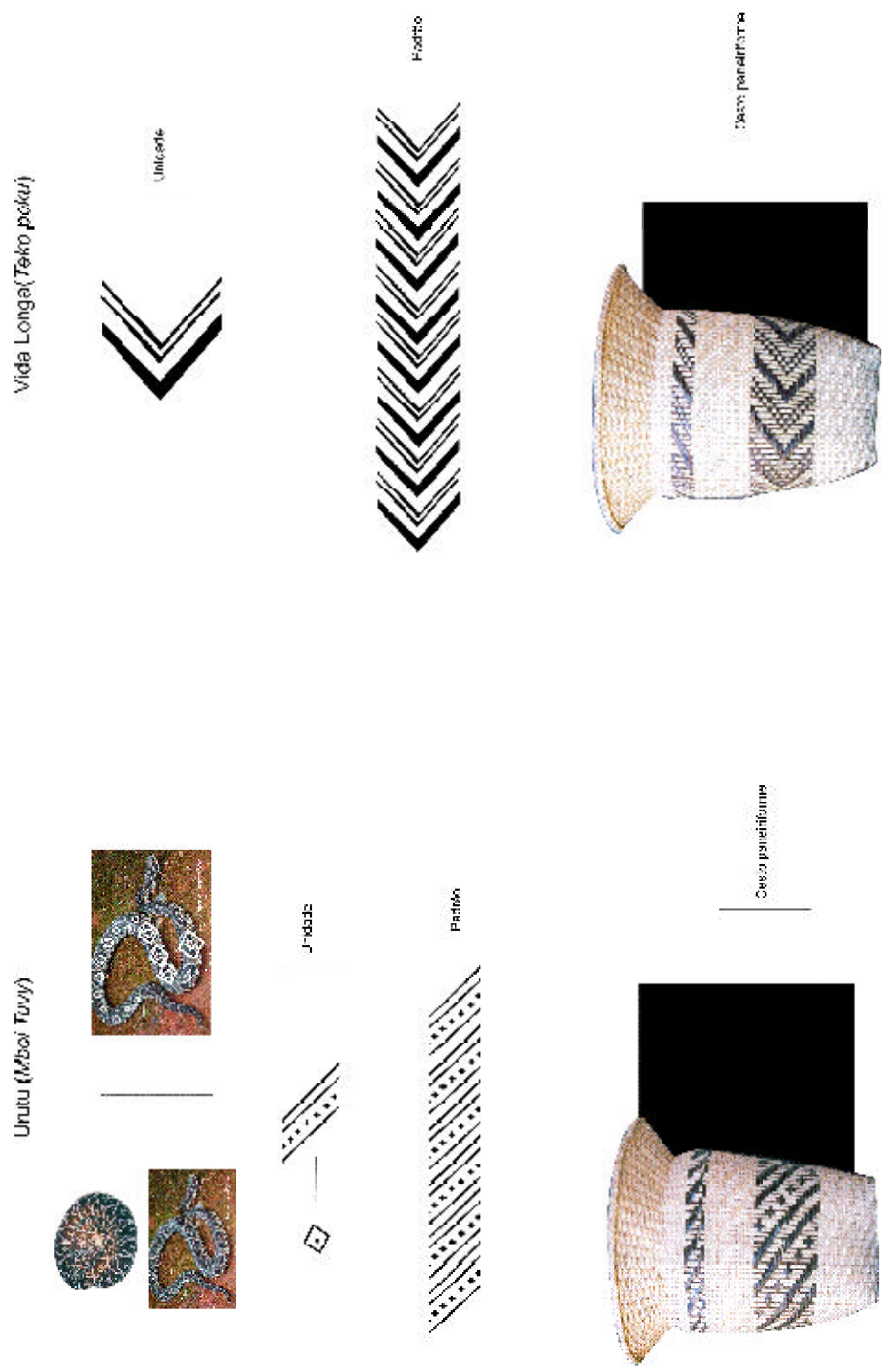

Tellus, ano 8, n. 15, jul./dez. 2008 

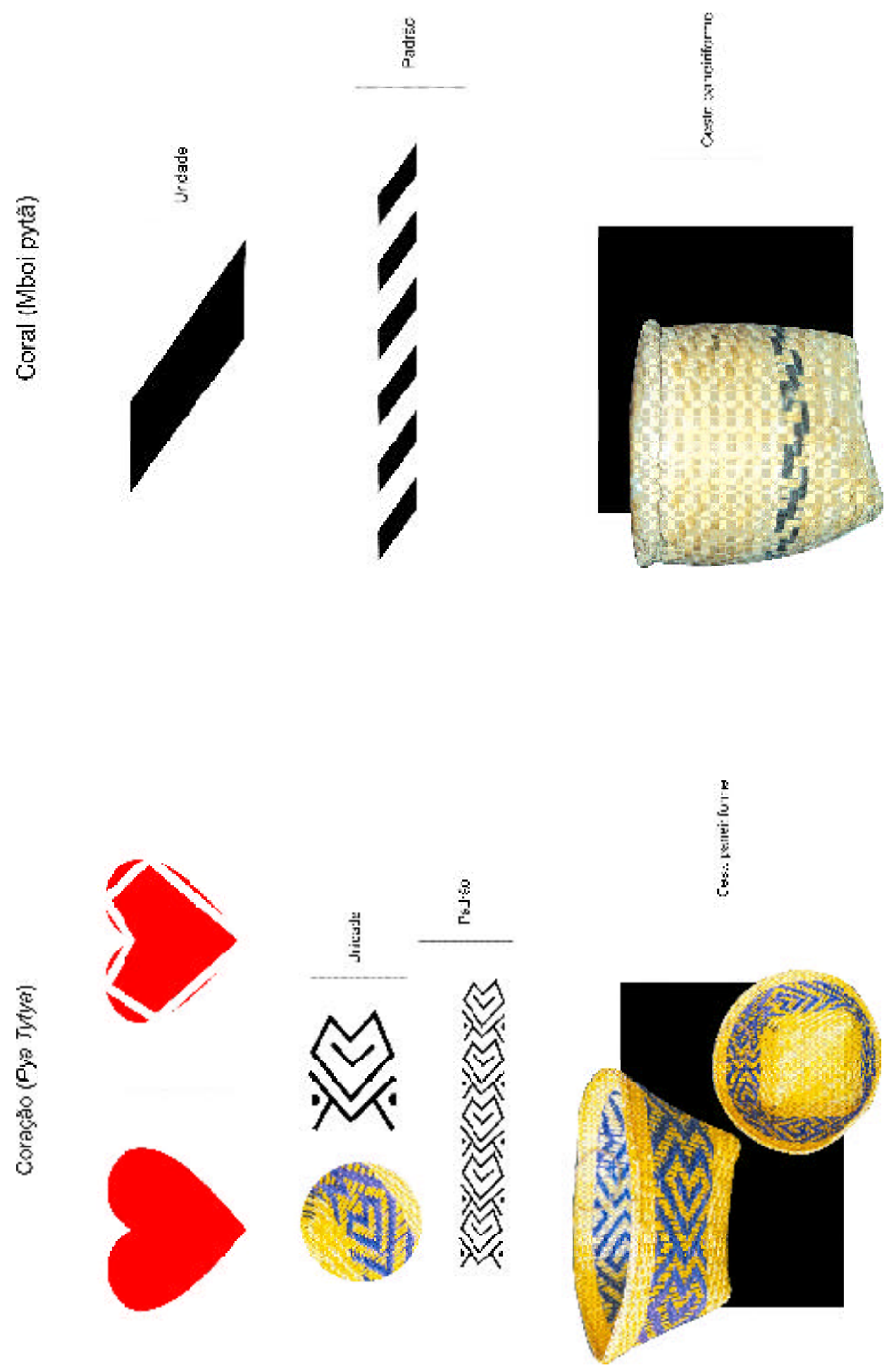

218 Francisco José SARMENTO. O grafismo das cestarias dos Guarani M’byá 
É interessante perceber que a cobra tem uma presença simbólica forte no universo cosmológico guarani. A cestaria de um modo geral era utilizada para levar fruta, o milho sagrado, o pão sagrado, nos rituais realizados na casa de reza (opy). Hoje em dia, além desse uso, os cestos têm um papel importante como fonte de renda da comunidade. A cobra comumente representada em torno do cesto tem a função simbólica de proteger os alimentos ali contidos. Os objetos da cultura M'byá trazem consigo também um significado religioso, sagrado. Em depoimento a este trabalho, o índio Darcy relata: "nada que é construído por nós está separado do sagrado. Tudo possui um sentido, um significado".

Para identificar os padrões utilizei a seguinte metodologia: coletei depoimentos de pessoas da Aldeia Itatins, diante de fotos dos cestos e às vezes do próprio cesto. Após esse procedimento de nomeação dos padrões, começou um trabalho de busca dos animais para fotografá-los. Depois da planificação do grafismo dos cestos (adjaká), descobria-se a unidade do padrão e, por conseguinte a busca da identificação da unidade com a malha do animal (no caso das cobras). Essa planificação era um processo feito em parceria com Darcy, professor na aldeia e filho de Para Poty. O desenho era identificado e, depois, com as fotos das cobras, na imagem identificávamos as células (unidade) que dão origem à trama. Esses termos - trama, unidade, célula - são retirados do Dicionário do Artesanato Indígena de Berta Ribeiro (1988).

Cada trama (ou padrão) é criado a partir de uma célula, que aqui iremos chamar de unidade, este fragmento é a transposição de um elemento encontrado na malha - "corpo" daquilo que se quer retratar - ou é uma forma abstrata, como a representação de vida longa.

As cobras utilizadas como inspiração dos M’byá de Paraty-Mirim, ocorrem com freqüência na Mata Atlântica. É importante salientar que no sul do país os M’byá representam também a cascavel (mboitini ipará), que tem uma maior ocorrência naquela região.

Uma pessoa fundamental para este trabalho foi a artesã indígena Para Poty, ela é uma das artesãs mais respeitadas na comunidade, trabalha com os cestos desde criança, mas como ela gosta de dizer, eles não eram feitos para vender e sim para usar. A vinda do sul e o assentamento em uma terra de baixa qualidade para o plantio estimulou a confecção das cestarias para o comércio.

É relevante perceber que há uma evolução nos temas propostos para serem representados nas cestarias. Dentro desse contexto de evolução gráfica, se faz pertinente o depoimento de Para Poty, ela nos surpreen- 
de ao contar uma história muito interessante relacionada aos desenhos dos cestos. Ela diz que quando alguém na tribo está com problemas no coração é feito um cesto com este desenho - trama em formato de coração (pya tytya). Quando o enfermo é levado à casa de reza é presenteado com este cesto o qual possui em seu interior o pão sagrado, as frutas e o mel, que ele leva para a cerimônia de cura. Excepcionalmente para este trabalho, a artesã fez um cesto com esse motivo para que pudesse ser registrado. Outro desenho ligado à saúde é a trama da vida longa (teko puku) que também é oferecido a uma pessoa, enferma ou não, com votos de que a pessoa presenteada tenha uma vida longa.

Quando conversamos sobre as tonalidades das cestarias, Para Poty contou que antigamente não se utilizavam cores nos cestos e que eram feitos somente com o cipó ambê e vendepé, como se pode ver nas imagem anterior, que representa o grafismo urutu. Para Poty narra que quando começou a utilizar as cores nos cestos, encontrava todos os pigmentos que necessitava na própria natureza, quando morava no sul do país. Tal declaração desfaz o mito de que os M'byá só utilizam pigmentos artificiais. Na verdade, o uso de cores já se tornou uma tradição e nada tem a ver com uma ruptura imposta pela necessidade de venda como querem alguns. Para Poty complementa:

Há muito tempo utilizo cores no trabalho, mas aqui não temos as cores no mato. Só temos a carobinha que eu planto para fazer o amarelo. Lá no sul tinha...

As demais tonalidades são produzidas por um método artificial com o uso de anilina. A artesã diz que as cores são usadas de forma aleatória: "uso as que eu acho que ficam bonito, que dê para ver o desenho", resume.

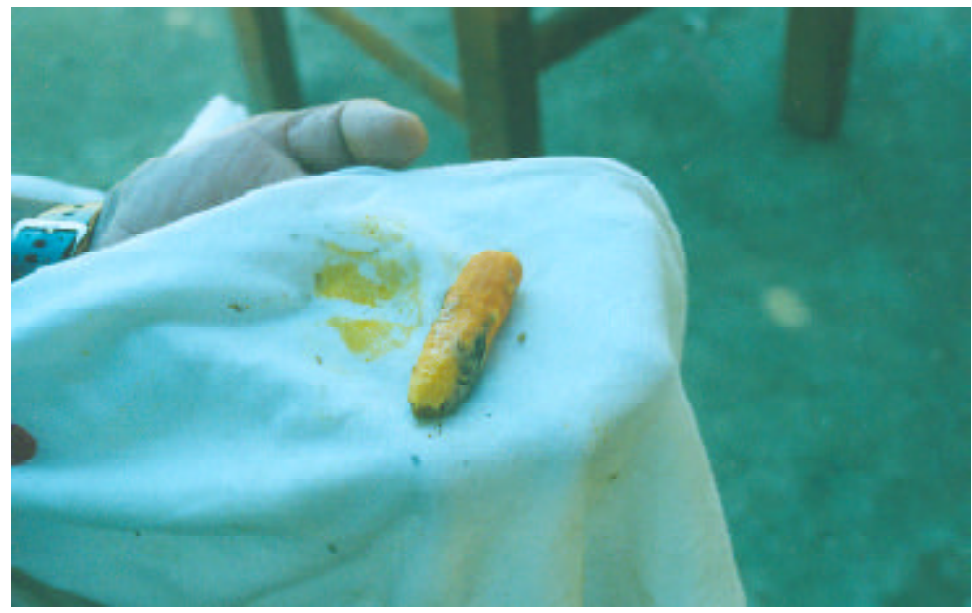




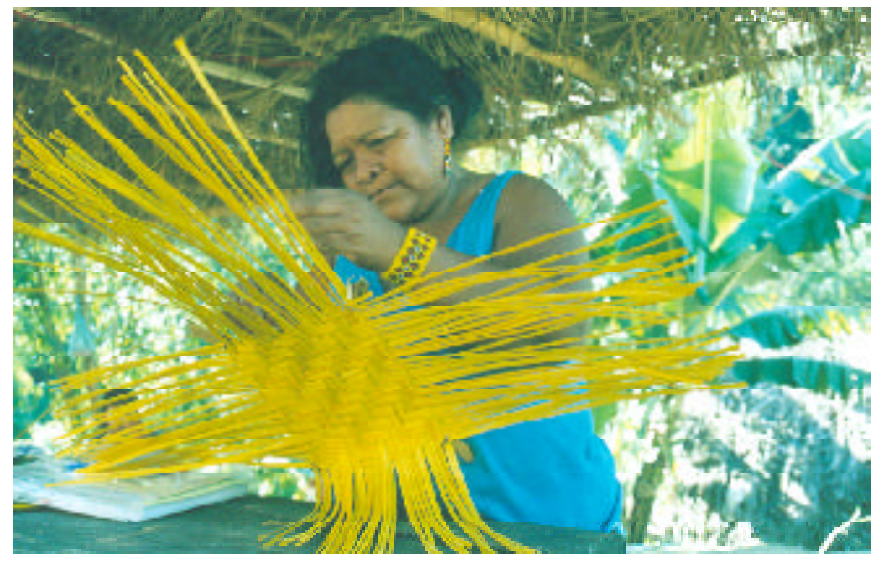

Para Poty é um exemplo de artista para a aldeia, seus trabalhos são reverenciados por todo o grupo, inclusive em aldeias vizinhas, que se inspiram nas combinações cromáticas e gráficas criadas por ela. À primeira vista parece que as combinações se repetem, mas muitas vezes essas tramas podem mudar sem perder o sentido. Tais mudanças variam desde uma linha a mais, até os tamanhos das tramas dos desenhos. Há um processo dinâmico, como qualquer processo cultural. Essas manifestações visuais como qualquer outro fenômeno cultural, são aqui encaradas como processo, no qual articulam-se estilo coletivo/repetição com capacidade criadora individual/variação, "manifestações visuais que analisam como sendo expressão estética gráfica de identidades étnicas e culturais" (Vidal e Lopes Silva, 2000, p.280).

Quando perguntada sobre a simbologia dos desenhos para os M'byá, a artesã relata que os significados são passados das mães para as crianças. No momento da confecção das cestarias todos trabalham juntos, todos ficam em torno do artista: uma combinação perfeita de aprendizado com as mãos, ou seja, na prática, a construção do conhecimento compartilhado M’byá.

\section{Referências}

RIBEIRO, Berta. Suma Etnológica Brasileira, v. 3. RIBEIRO, Darcy et al. (eds.) Petrópolis: Vozes, 1987.

. Dicionário do Artesanato Indígena. São Paulo: Edusp, 1988.

VIDAL, Lux; SILVA, Aracy Lopes da. Antropologia estética: enfoques teóricos e contribuições metodológicas. In: VIDAL, Lux. Grafismo indígena. Estudos de antropologia estética. São Paulo: Edusp, 2000.

Recebido em 14 de agosto de 2008.

Aprovado para publicação em 22 de agosto de 2008.

Tellus, ano 8, n. 15, jul./dez. 2008 
